\title{
Seismicity from February 2006 to September 2007 at the Rwenzori Mountains, East African Rift: earthquake distribution, magnitudes and source mechanisms
}

\author{
M. Lindenfeld ${ }^{1}$, G. Rümpker ${ }^{1}$, A. Batte ${ }^{2}$, and A. Schumann ${ }^{1}$ \\ ${ }^{1}$ Institute of Geosciences, Goethe-University, Frankfurt am Main, Germany \\ ${ }^{2}$ Department of Geology, Makerere University, Kampala, Uganda \\ Correspondence to: M. Lindenfeld (lindenfeld@geophysik.uni-frankfurt.de) \\ Received: 14 March 2012 - Published in Solid Earth Discuss.: 8 May 2012 \\ Revised: 12 July 2012 - Accepted: 26 July 2012 - Published: 21 August 2012
}

\begin{abstract}
We have analysed the microseismic activity within the Rwenzori Mountains area in the western branch of the East African Rift. Seismogram recordings from a temporary array of up to 27 stations reveal approximately 800 events per month with local magnitudes ranging from -0.5 to 5.1 . The earthquake distribution is highly heterogeneous. The majority of located events lie within faults zones to the east and west of the Rwenzoris with the highest seismic activity observed in the northeastern area, where the mountains are in contact with the rift shoulders. The hypocentral depth distribution exhibits a pronounced peak of seismic energy release at $15 \mathrm{~km}$ depth. The maximum extent of seismicity ranges from 20 to $32 \mathrm{~km}$ and correlates well with Moho depths that were derived from teleseismic receiver functions. We observe two general features: (i) beneath the rift shoulders, seismicity extends from the surface down to ca. $30 \mathrm{~km}$ depth; (ii) beneath the rift valley, seismicity is confined to depths greater than $10 \mathrm{~km}$. From the observations there is no indication for a crustal root beneath the Rwenzori Mountains. The magnitude frequency distribution reveals a $b$-value of 1.1 , which is consistent with the hypothesis that part of the seismicity is caused by magmatic processes within the crust. Fault plane solutions of 304 events were derived from P-polarities and SV/P amplitude ratios. More than $70 \%$ of the source mechanisms exhibit pure or predominantly normal faulting. T-axis trends are highly uniform and oriented WNW-ESE, which is perpendicular to the rift axis and in good agreement with kinematic rift models. At the northernmost part of the region
\end{abstract}

we observe a rotation of the T-axis trends to NEN-SWS, which may be indicative of a local perturbation of the regional stress field.

\section{Introduction}

The East African Rift System (EARS) separates the Nubian and the Somalian plates and represents one of the world's largest continental rift structures (Bendick et al., 2006; Chorowicz, 2005; Ebinger, 1989). Starting at the Afar triple junction in the north, it extends approximately in $\mathrm{N}-\mathrm{S}$ direction through East Africa, consisting of a series of connecting rifts segments (Fig. 1). South of the Main Ethiopian Rift, the system splits up into two branches: the Albertine Rift in the west and the Kenya Rift in the east. They enclose the Tanzania Craton which is surrounded by Proterozoic mobile belts (Nyblade and Brazier, 2002). Further south the system continues as the Malawi Rift and terminates at the coast of southern Mozambique.

Globally recorded earthquakes (Fig. 1) as well as compilations on regional and local earthquake studies have shown that the western branch of the EARS exhibits significantly higher seismic activity than the eastern branch (Midzi et al., 1999; Twesigomwe, 1997). Numerous publications focus on the hypocentral depth distribution, which turns out to extend down to the crustal base - in contrast to other seismically active continental regions where earthquakes are 


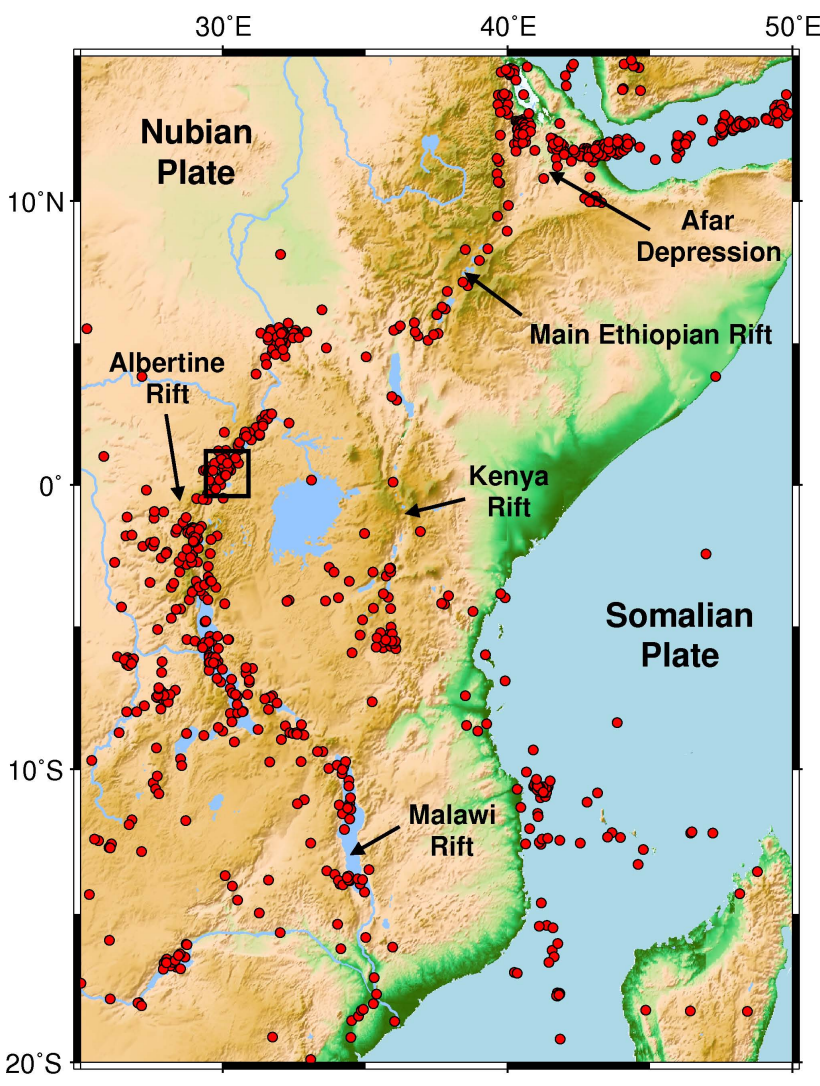

Fig. 1. The East African Rift System. Red dots: global seismicity; 1973-2008, with $M \geq 4.5$ (NEIC catalogue). The small black square within the Albertine Rift marks the Rwenzori area (Fig. 2).

restricted to the upper crust (e.g. Albaric et al., 2009; Camelbeek and Iranga, 1996; Foster and Jackson, 1998; Nyblade and Langston, 1995; Shudofsky et al., 1987; Young et al., 1991).

The $5000 \mathrm{~m}$ high Rwenzori Mountains are situated within the Albertine rift, in an area with the highest seismic activity of the whole rift system. They represent a non-volcanic basement block whose origin and relation to the evolution of the EARS are the focus of the RiftLink project (www. riftlink.org). Despite of the high activity, there is only little knowledge on the local seismicity in the Rwenzori region. An early microearthquake survey in the Rwenzori area (Maasha, 1975) was based on four portable seismic stations. They were operated at 28 different sites during June to September 1973, moving the instruments after a period of 4 to 20 days to new locations. An average of 5 to 20 events per day was recorded in the area with magnitude estimates between -2 and 4 and focal depth reaching down to 25 to $40 \mathrm{~km}$. However, these depth estimates exhibit large uncertainties because of the limited number of stations. A small number of composite fault plane solutions indicated normal faulting in the Rwenzori area. A more recent study by Tugume and Nyblade (2009) was restricted to the north-

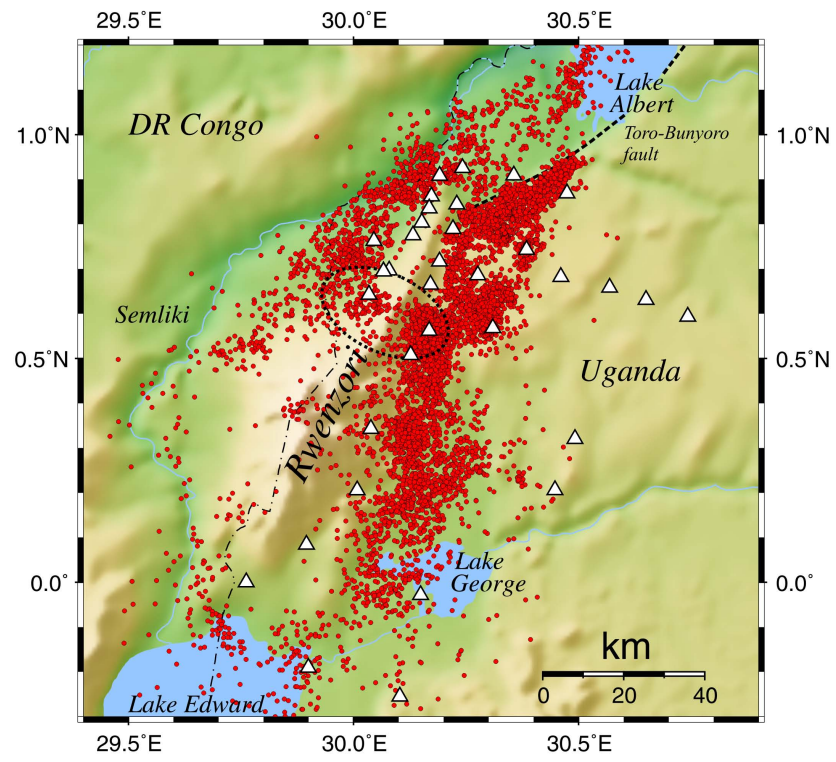

Fig. 2. The Rwenzori region with seismic station network (triangles) and recorded local seismicity (red circles) from February 2006 to September 2007. The dashed line in the NE marks the southern end of the Toro-Bunyoro fault; the dotted ellipse in the centre covers the area of increased seismicity within the Rwenzori block (see Sect. 3.1 in text).

ern end of the Rwenzori Mountains. The authors present the seismic activity between March and June 2006 based on a network of eight stations and they investigate the hypocentral depth extent and its implication on the heat flow in the area. The observed focal depth distribution exhibits a maximum number of earthquakes at $16 \mathrm{~km}$ and falls off sharply at $22 \mathrm{~km}$ extending down to $31 \mathrm{~km}$. In all of the above investigations the depth extent of seismicity is restricted to the crust. However, Lindenfeld and Rümpker (2011) have reported the detection of mantle earthquakes to the northeast of the Rwenzori Mountains, which are likely related to magmatic intrusions in relation to lithospheric break up.

In the present paper we provide a comprehensive characterization of the seismic activity within the whole Rwenzori region, covering a substantially larger area and time period than previous investigations. For the first time we present magnitude distributions and reliable source mechanisms of a large set of earthquakes, together with a detailed discussion of the complex hypocentral depth distribution. These data are essential for a better understanding of the rifting processes in this part of the EARS and will improve our general insight into the mechanisms of active rifts.

\section{Seismic network and data analysis}

The data we present in this study were recorded from February 2006 to September 2007 by a temporary network of 29 seismic stations covering an area of $140 \times 80 \mathrm{~km}^{2}$ in the 
Rwenzori Mountains region. The instruments were installed in the framework of the RiftLink Project, however, some data were also provided by the BGR/GSMD GEOTHERMSubprogram (German Geological Survey, BGR, Geological Survey and Mines Department, GSMD, Uganda). Until April 2006, a small network of nine 3-component shortperiod instruments was running in the northern part of the area equipped with Reftek data loggers sampling the data at $100 \mathrm{~Hz}$ in triggered mode. Starting in May 2006, the net was expanded by 20 stations equipped with EDL data loggers recording continuously at a sample rate of $100 \mathrm{~km}$. Seven of these stations were equipped with broadband instruments (Guralp CMG-3T), the remainder with short-period seismometers (Mark L-4C3-D). Occasionally, some instruments were moved to new places so that the network in total consisted of 35 station locations (Fig. 2).

\subsection{Hypocentre location}

In order to detect and extract the numerous local events we applied a STA/LTA trigger algorithm to the continuous data streams. Prior to this procedure, the data were filtered with a Butterworth high pass at $1 \mathrm{~Hz}$. Tests were performed to determine the optimum set of trigger parameters, i.e. to identify a maximum number of earthquakes without too much false trigger events. Time windows for short- and long-term average (STA, LTA) were set to $3 \mathrm{~s}$ and $30 \mathrm{~s}$ respectively, a ratio of STA/LTA $=3.0$ was chosen to trigger an event. The routine data analysis was done with the SEISAN software package (Havskov and Ottemöller, 1999), including an implementation of HYPOCENTER, a location algorithm by Lienert and Havskov (1995). Arrival times were manually picked on the unfiltered seismograms to avoid phase shift effects, $\mathrm{P}$ waves on the vertical component and $\mathrm{S}$ on one of the horizontal components. For earthquake location we used the velocity model UVI-N74 of Bram (1975) with a fixed vp/vs ratio of 1.74 (Table 1). The Bram model was derived from local and regional $\mathrm{P}_{n}$ phases travelling predominantly parallel to the Albertine rift. To test the limits of such a relatively simple 1-D velocity model, we relocated the hypocentres using a synthetic 3-D model with several crustal velocity anomalies between $-7 \%$ and $+7 \%$ (Jakovlev, 2010). The average deviation of the relocated hypocentres compared to the 1-D locations was about $1.30 \mathrm{~km}$, which is smaller than the estimated 1 -D location error ( $<3 \mathrm{~km}$, see below). Furthermore, 3-D velocity anomalies from travel-time tomography are only well constrained in the centre of the seismic station network with relatively poor vertical resolution (Jakovlev et al., 2011). For these reasons we think that the use of a 3-D velocity model would not improve the location precision of the Bram model.

To give an impression of the data quality, we present seismograms of two earthquakes (Fig. 3). The first event (top row) was relatively weak $\left(M_{L}=0.9\right)$. The plotted seismograms were recorded at stations KARU $(\Delta=12.9 \mathrm{~km})$ and KISA $(\Delta=49.2 \mathrm{~km})$. Both stations show clear P- and S-
Table 1. Velocity model UVI-N74 of Bram (1975) used for earthquake location. S-velocities were calculated with a constant $v_{P} / v_{S}$ ratio of 1.74 as derived by Bram.

\begin{tabular}{lcc}
\hline depth $[\mathrm{km}]$ & $v_{P}\left[\mathrm{~km} \mathrm{~s}^{-1}\right]$ & $v_{S}\left[\mathrm{~km} \mathrm{~s}^{-1}\right]$ \\
\hline 0 & 6.00 & 3.45 \\
16 & 6.75 & 3.88 \\
32 & 8.05 & 4.63 \\
60 & 7.75 & 4.45 \\
125 & 8.20 & 4.71 \\
\hline
\end{tabular}

onsets with good signal-to-noise ratios that enable reliable arrival time pickings (dashed lines). The second event (bottom row) was relatively strong $\left(M_{L}=3.8\right)$. Records are from stations KASS $(\Delta=2.8 \mathrm{~km})$ and KISA $(\Delta=49.3 \mathrm{~km})$.

In general it was possible to determine $\mathrm{P}$-arrival times with a precision of $\pm 0.05 \mathrm{~s}$. We assume a slightly reduced accuracy for $\mathrm{S}$-wave arrivals of $\pm 0.1 \mathrm{~s}$. This is due to the lower frequency content of the $S$-phases and because in many cases the true S-onset is blurred by the P-wave coda. During the location process the SEISAN software provides estimates of location errors based on travel time residuals and the station network geometry. The RMS residuals range between $0.1 \mathrm{~s}$ and $0.2 \mathrm{~s}$ in most cases. In the following analysis we use only events with location errors $\leq 5 \mathrm{~km}$ which is $76 \%$ of all located events. The average location errors for these events are $1.7 \mathrm{~km}$ (horizontally) and $2.4 \mathrm{~km}$ (vertically), respectively. The number of stations used to locate an earthquake increases with the magnitude. Typically, the smallest events $\left(M_{L}<1.0\right)$ are located with 4-5 stations. Events with magnitudes from 1.0-2.0 are located by up to 13 stations. For the strongest events, we used up to 20 stations. In some cases recordings of the complete network (27 stations) were available.

\subsection{Magnitude determination}

Local magnitudes were determined using the formula of Hutton and Boore (1987):

$M_{L}=a * \log (\mathrm{amp})+b * \log (\mathrm{dist})+c * \operatorname{dist}+d$,

where amp is the maximum horizontal ground amplitude (zero-peak) in $\mathrm{nm}$ of a Wood-Anderson simulation of the recorded seismogram, and dist is the hypocentral distance in $\mathrm{km}$. So far, there are no calibration parameters $(a, b, c$, d) available for the Rwenzori region. We use the presets of the SEISAN software package:

$a=1.0, b=0.91, c=0.00087$, and $d=1.67$,

which were derived by Alsaker et al. (1991) (Ottemöller, 2010, personal communication). Figure 4 presents the magnitude of an event calculated at twelve different stations as a function of epicentral distance (circles). The average of all 

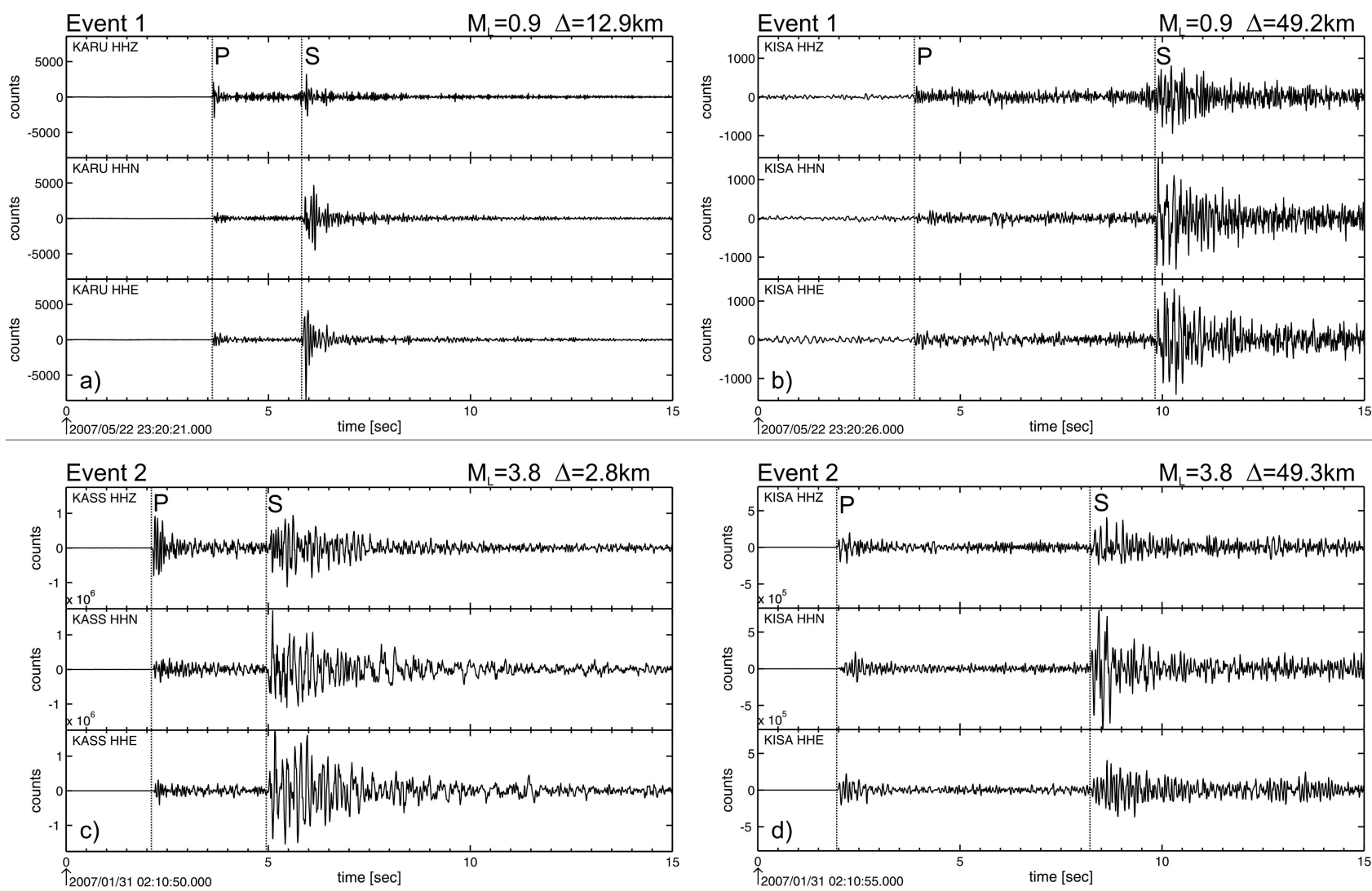

Fig. 3. Seismogram examples of two events, each recorded at two different epicentral distances. Top row (a, b): Relatively week event 1 $\left(M_{L}=0.9\right)$, recorded at stations KARU $(\Delta=12.9 \mathrm{~km}$, left $)$ and KISA $(\Delta=49.2 \mathrm{~km}$, right $)$. Bottom row $(\mathbf{c}, \mathbf{d})$ : Strong event $2\left(M_{L}=3.8\right)$ recorded at stations $\operatorname{KASS}(\Delta=2.8 \mathrm{~km}$, left) and KISA $(\Delta=49.3 \mathrm{~km}$, right). Seismometer channels Z, N, and E are plotted from top to bottom of each record. Amplitudes are plotted in digital counts. Picked P- and S-phases are marked by dashed lines.

stations is $M_{L}=2.3$ with a standard deviation of \pm 0.3 . Obviously, there is no systematic distance dependence of the calculated magnitudes. This suggests that the calibration parameters of Alsaker et al. (1991) give an appropriate description of the attenuation in the Rwenzori area. For comparison we re-calculated the magnitudes using calibration parameters that were derived for Tanzania (Langston et al., 1998) and the original values for Southern California (Hutton and Boore, 1987). The results are also plotted in Fig. 4 and show no significant deviation from the magnitudes calculated with the default parameters of SEISAN.

\subsection{Temporal variations of seismic activity}

The analysis of the recorded data revealed high microseismic activity in the Rwenzori region. Figure 5 presents the monthly numbers of located earthquakes which correlates fairly well with the number of operating stations. Starting in February 2006, the number of events increases until July when the expansion of the station network was finished. Between August 2006 and September 2007, when the network was running in a more or less steady state, we located on av- erage 766 events per month, 613 of them with errors $\leq 5 \mathrm{~km}$ (light and dark bars, respectively). We are not able to identify any clear seasonal variations of the seismicity rate. However, we observe a distinct dependence on the time of day (Fig.6). There is an apparent breakdown in seismic activity between 04:00 and 17:00 UT which corresponds to 07:00-21:00 LT. The number of located events decreases to less than $25 \%$ of the night time values. We associate this observation with an increased noise level during day time. During this period the sensitivity of the seismometer network is considerably reduced as a result of human activity, such as field work and traffic, which starts shortly after sunrise (ca. 06:00) and ends a few hours after sunset (ca. 18:00). However, this affects only events with magnitudes smaller than 1.5 , whereas the number of larger earthquakes is more or less constant over the whole day. 


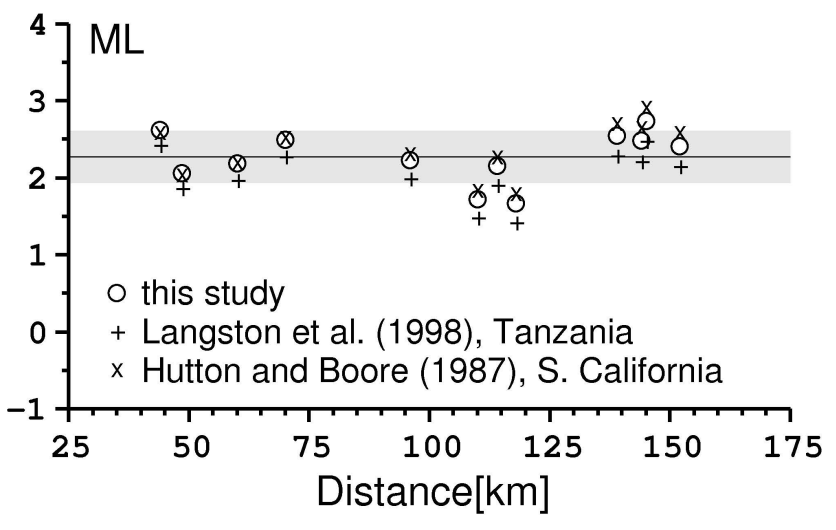

Fig. 4. Magnitude of an event calculated at twelve different stations with epicentral distances between $44 \mathrm{~km}$ and $152 \mathrm{~km}$. In this study we used the default calibration functions of the SEISAN software (circles) based on Alsaker et al. (1991). The average of all stations comes to $M_{L}=2.3$ (horizontal line) with a standard deviation of \pm 0.3 (grey area). For comparison we have also computed magnitudes using the calibration parameters of Langston et al. (1998) for Tanzania (plus-signs) and the calibration parameters for S. California derived by Hutton and Boore (1987).

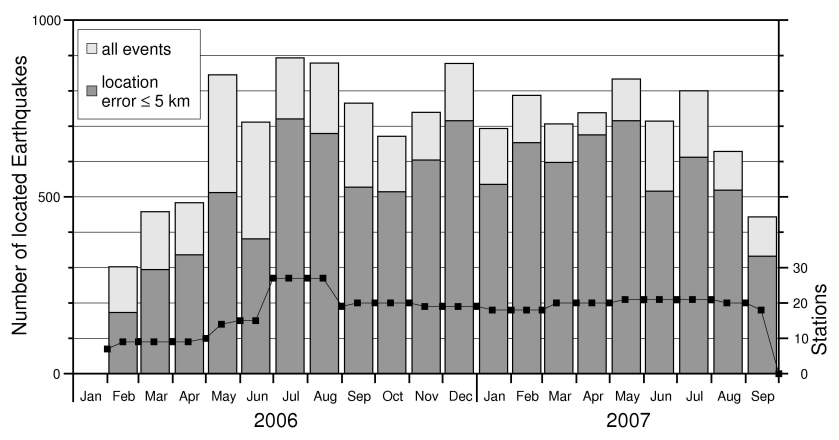

Fig. 5. Monthly numbers of located events. Light grey bars indicate all located earthquakes; dark grey bars indicate events that could be located with errors $\leq 5 \mathrm{~km}$. The number of operating stations at the beginning and middle of each month is marked by black symbols.

\section{Results and discussion}

\subsection{Hypocentre distribution}

In total we located almost 14000 earthquakes from February 2006 to September 2007 in the Rwenzori area. The seismicity map (Fig. 2) includes ca. 10600 events with location errors $\leq 5 \mathrm{~km}$. Only few earthquakes are located within the Rwenzori block. The majority of the epicentres lie within fault zones to the east and west of the mountain range. This may possibly indicate that the mountains can be considered as a decoupled rigid block that is surrounded by two rift segments and resistant to seismogenic deformations as proposed by Koehn et al. $(2008,2010)$. However, between $0.5^{\circ}$ and $0.6^{\circ}$ latitude, we detected a narrow band of seismicity, separating the main Rwenzori block in the south from its northern

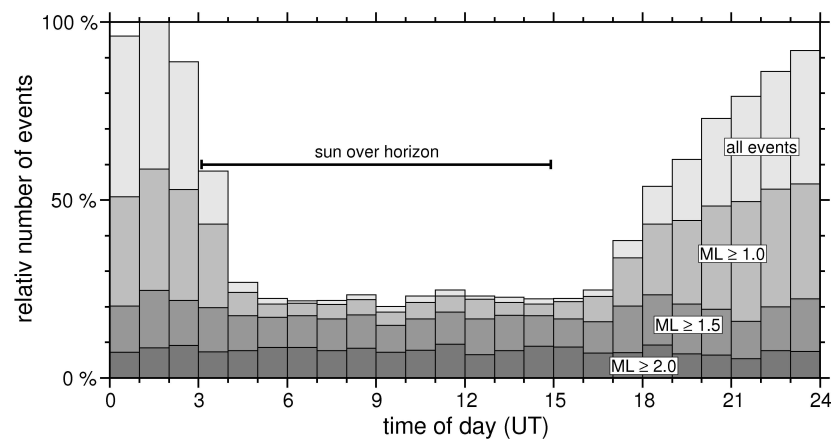

Fig. 6. Number of located events as function of daytime. There is an obvious diurnal variation for earthquakes with magnitudes smaller than 1.5 caused by human activity which reduces the sensitivity of the station network during daytime.

ridge, see dotted ellipse in Fig. 2. This is probably an indication of stresses and relative movements acting between the two mountain segments. The highest seismic activity is observed within a region east of the Rwenzoris between Lake Albert and Lake George, where the mountains are connected to the eastern rift flank. The majority of these events are grouped in clusters rather than in planar structures. Only in few cases it is possible to associate the epicentre distribution with known faults. At the northeastern tip of the mountains, between $0.8^{\circ}-1.0^{\circ}$ latitude and $30.2^{\circ}-30.5^{\circ}$ longitude, we recorded high seismicity aligned with the $\mathrm{N}-\mathrm{E}$ trending eastern rift flank. These events are probably located at the southern segment of the Toro-Bunyoro fault (Fig. 2), which runs in NE direction along the eastern side of the Lake Albert Basin (e.g. Ring, 2008). However, at about $1.0^{\circ} \mathrm{N}$ seismic activity on the fault ends abruptly and continues more diffuse into the Lake Albert Rift. In the southwestern parts of the Rwenzori region we observed only weak seismic activity. As will be shown in Sect. 3.3., this is probably an artefact due to the absence of stations in that area, which decreases the sensitivity of the station network and enables the detection of only the stronger events. Currently we are operating a new network that covers the whole Rwenzori region including the western and southwestern parts situated in the Democratic Republic of Congo. The analysis of the data will answer the question if seismic activity in this region is actually weak or has a similar high level, as observed in the northeastern parts of the Rwenzori area.

\subsection{Depth distribution}

In Fig. 7 we present a histogram of the general hypocentral depth distribution in the Rwenzori area. Seismicity extends from the surface down to a depth of $32 \mathrm{~km}$ with a clear maximum of activity at $15 \mathrm{~km}$. However, the velocity model of Bram (1975) which was used for location has a discontinuity at $16 \mathrm{~km}$ depth (see inset of Fig. 7 and Table 1). Such a velocity jump may induce earthquake concentrations at the 


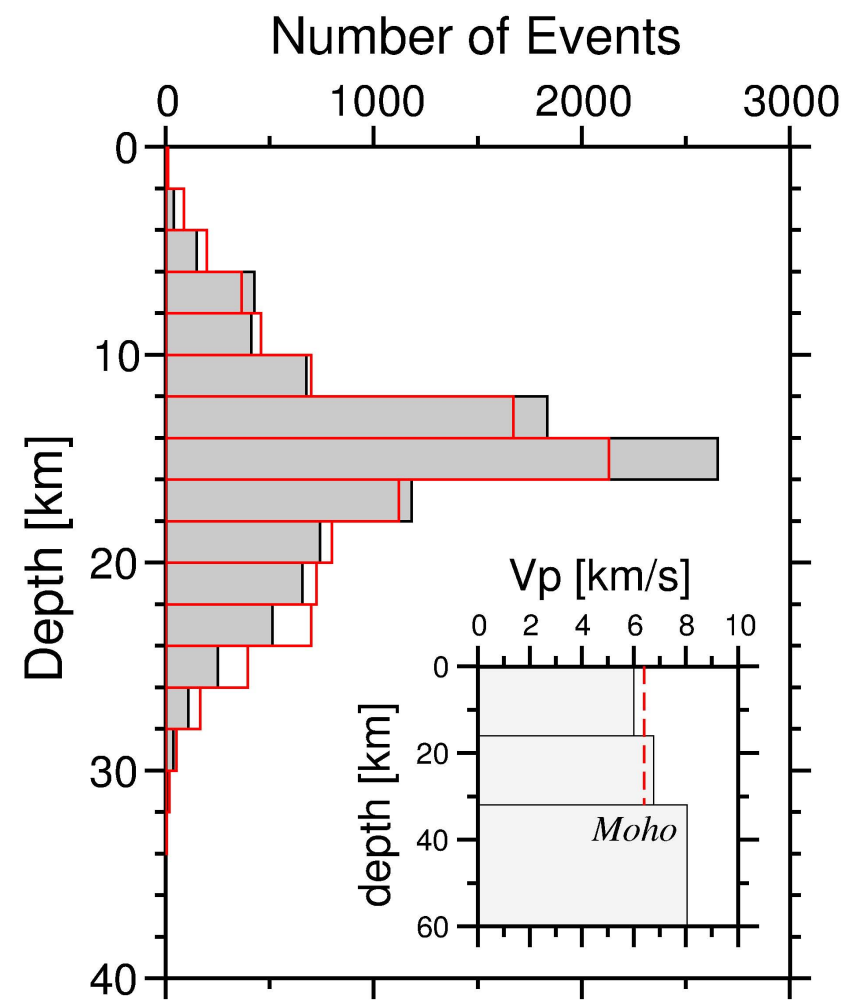

Fig. 7. Hypocentral depth distribution derived by using the BRAM (1975) velocity model (grey bars). See inset and Table 1 . The red outlines illustrate the depth distribution of the same events, located with varying start depth and constant velocity within the crust (dashed red line in the inset).

corresponding depth, especially in regions with spare station coverage. For this reason we have checked the stability of our locations by relocating the events with a simple constant velocity model (dashed red line in the inset of Fig. 7). The starting depth of the location iteration was systematically increased from $5 \mathrm{~km}$ to $25 \mathrm{~km}$ with an increment of $5 \mathrm{~km}$ and the solutions with minimum RMS residual times were finally selected. The resulting hypocentral depth distribution confirms the previous locations (Fig. 7, red bars). The maximum of seismicity still occurs at $14-16 \mathrm{~km}$ depth, although a small part of the hypocentres has been shifted to greater depths. For this reason we are convinced that the hypocentral depths are reliable, at least in the central region of the network.

The derived depth distribution agrees well with earlier observations leading to the conclusion that in East Africa, earthquakes occur throughout the crust, but not deeper than the Mohorovicic discontinuity (Albaric et al., 2009; Brazier et al., 2005; Foster and Jackson, 1998). While in most other continental regions seismicity is restricted to the upper crust, similar focal depth distributions throughout the complete crust are also reported for the Baikal Rift (Chen and Molnar, 1983; Emmerson et al., 2006; Jackson et al., 2008; Maggi et al., 2000). Déverchère et al. (2001) find a seismo-

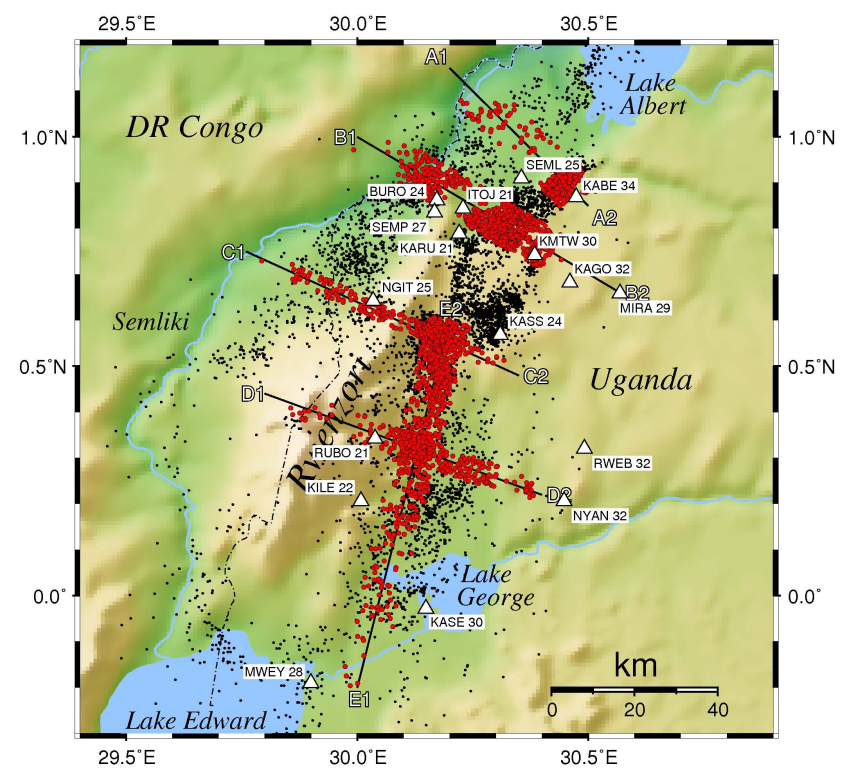

Fig. 8. Position of the vertical sections presented in the next Fig. 9. Four profiles (A-D) cross the Rwenzori area approximately perpendicular to the rift axis. One profile (E) runs in SSW-NNE direction parallel to the rift axis and penetrates the Lake George rift segment which extends northward from Lake Edward to Lake George. Coloured symbols denote events which are projected onto the respective vertical plane. Moho depths at different stations (white triangles) were derived by Wölbern et al. (2010) using teleseismic receiver functions. The numbers beside the station labels are Moho depths in $\mathrm{km}$.

genic lower crust with significant earthquake activity down to $35-40 \mathrm{~km}$ and only few earthquakes below the Moho in the Baikal Rift system, very similar to our results. From modelling of the brittle-ductile transition in the crust they infer a quartz rheology at $0-10 \mathrm{~km}$ depth and a diabase rheology at $10-45 \mathrm{~km}$ depth.

For a more detailed analysis of the hypocentral depth distribution we compiled several vertical sections of seismicity transecting the area in different places and directions (Fig. 8). Four profiles (A-D) are oriented more or less perpendicular to the rift axis, whereas profile $\mathrm{E}$ runs parallel to the rift from NNE to SSW. Black dots in Fig. 8 mark the background seismicity; coloured symbols represent hypocentres that were projected onto the respective planes. The vertical sections are presented in Fig. 9. In addition to the hypocentres, we have marked the Moho depths determined at several stations by teleseismic receiver functions (Wölbern et al., 2010). The locations of these stations are also indicated in Fig. 8. In contrast to the overall depth distribution of Fig. 7, we now observe a highly complex and individual picture at the different vertical sections. The approximate horizontal positions of rift shoulder and rift valley along the profiles are marked in Fig. 9 by dark and light shaded areas, respectively, for better orientation. 

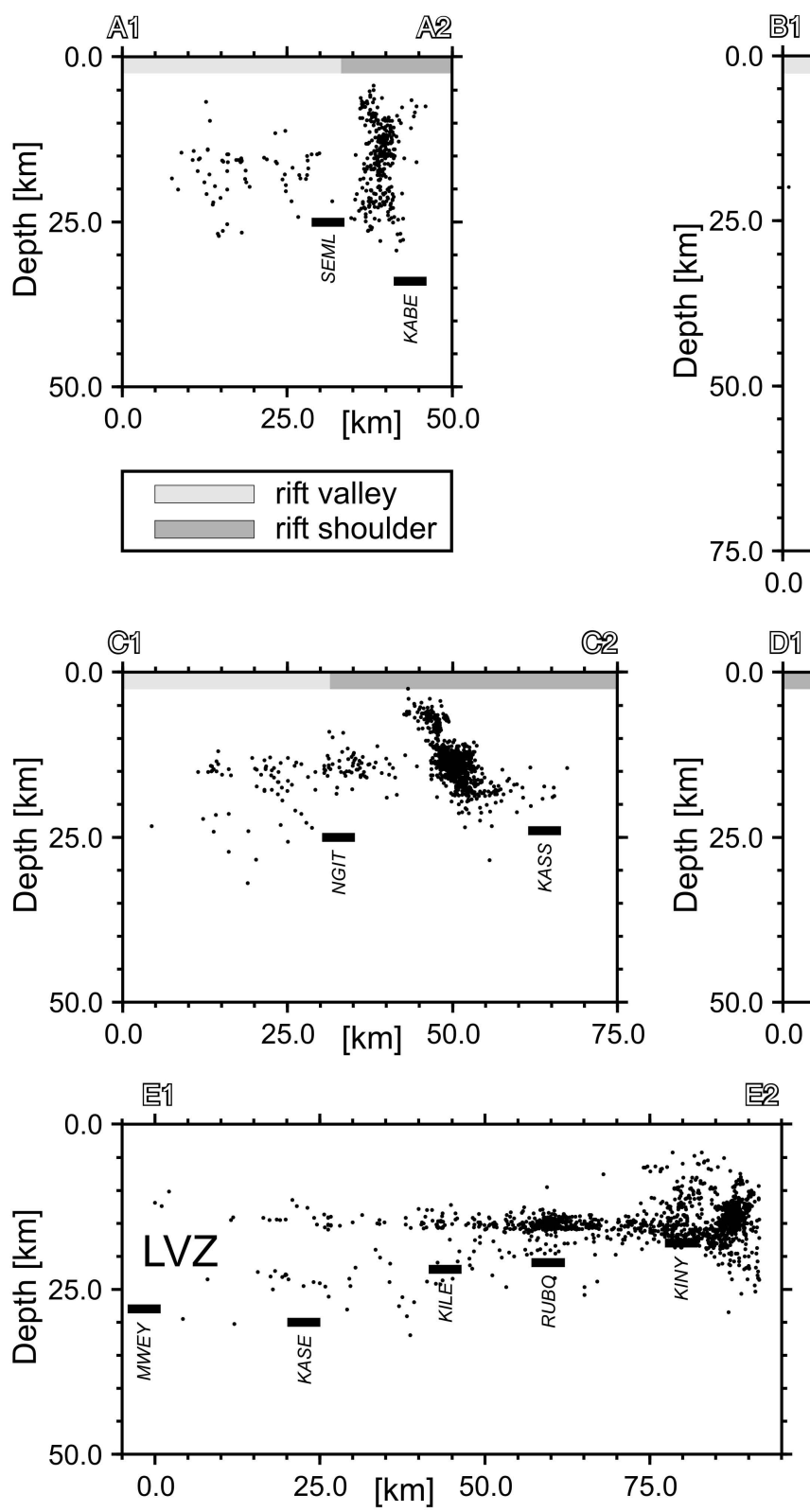
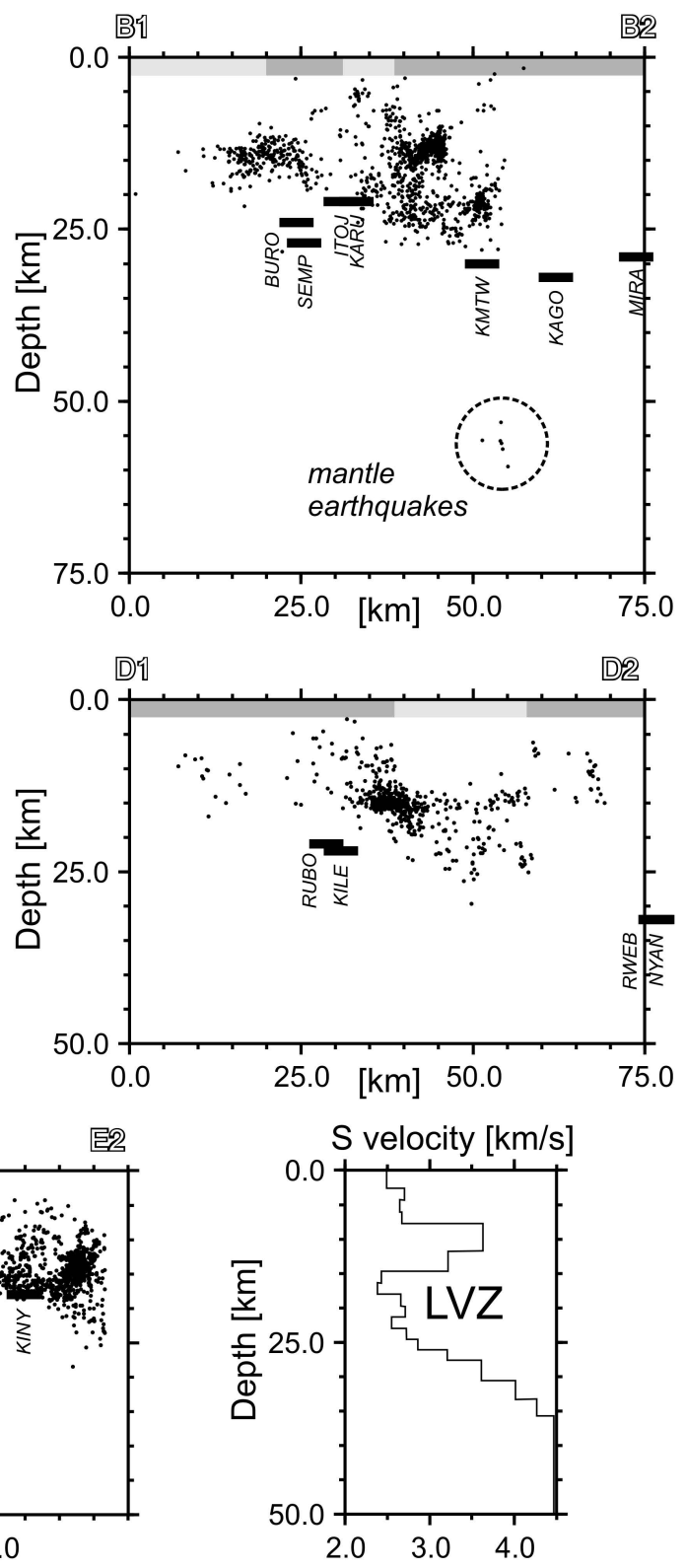

Fig. 9. Hypocentre depth sections A-E. The position of the profiles is plotted in Fig. 8. Heavy black bars indicate Moho depths as derived from teleseismic receiver functions at different seismic stations (Wölbern et al., 2010). The dashed circle in section B marks the position of seven mantle earthquakes which were detected in 53-60 km depth (Lindenfeld and Rümpker, 2011). The approximate horizontal position of rift shoulder (or Rwenzori horst) and rift valley is marked by dark and light shaded areas, respectively. The S-velocity model in the lowermost row was derived by receiver-function inversion at MWEY. It shows a distinct low velocity zone (LVZ) that is traced by two seismicity layers in profile $\mathrm{E}$.

Profile A: This profile crosses the Albertine Rift north of the Rwenzori mountains and ends up at the rift shoulder to the east. Beneath the shoulder $(35-45 \mathrm{~km}$ on the horizontal profile axis) seismicity is concentrated along a vertical oriented plane reaching from the surface down to $30 \mathrm{~km}$. In this area the Moho depth was determined at $34 \mathrm{~km}$ (station KABE) indicating that all events occur within the crust. On the western side however $(5-30 \mathrm{~km})$, beneath the rift valley, hypocentres are restricted between $10 \mathrm{~km}$ and $25 \mathrm{~km}$ depth. The Moho is also raised up to $25 \mathrm{~km}$ depth at SEML. (Moho depth at SEML was originally published with $34 \mathrm{~km}$. Wölbern (2011, personal communication) modified the Moho depth at this site after reinterpretation of the receiver functions on the basis of additional data). We observe this pattern of hypocentral depth distribution in all profiles. There are two general features. (1) Beneath the rift shoulders 
or in areas where the Rwenzoris are connected to the shoulders, seismicity extends from the surface down to ca. $30 \mathrm{~km}$ depth. (2) Beneath the rift valley, we observe no seismic activity within the uppermost $10 \mathrm{~km}$ together with reduced depth extension. The absence of shallow seismicity beneath the rift graben is also observed at Lake Bogoria (Young et al., 1991) and Lake Magadi (Ibs-von Seht et al., 2001), both located at the southern end of the Kenya rift. They attributed the activity deeper than $10 \mathrm{~km}$ to faults in the basement beneath the rift. Similar observations are reported by Kato et al. (2009) in the eastern margin of the Japan Sea back-arc basin, where they imaged a Miocene rift system buried beneath thick sedimentary layers. Ductile creeping of unconsolidated rocks may be the reason for the aseismic behaviour.

Profile B: This section is crossing the northern part of the Rwenzoris. Again, there is a distinct difference in the hypocentral depth distribution: west of the mountains (towards the rift valley, $5-25 \mathrm{~km}$ ) focal depths range from 10 to $20 \mathrm{~km}$. On the eastern side $(40-55 \mathrm{~km})$, where the Rwenzori Mountains are connected to the rift shoulder, seismicity extends from the surface down to $30 \mathrm{~km}$ depth. In between we observe only weak seismic activity which is typical for the Rwenzori block. Moho depths show the same characteristics. In the rift valley they range from $21 \mathrm{~km}$ to $27 \mathrm{~km}$ (BURO, SEMP, ITOJ, KARU) and beneath the rift shoulder from $29 \mathrm{~km}$ to $33 \mathrm{~km}$ (KMTW, KAGO, MIRA). A remarkable feature is the detection of mantle earthquakes in this area. A small group of seven earthquakes is located at depths between $53 \mathrm{~km}$ and $60 \mathrm{~km}$ (dashed circle) which is clearly below the Moho. These events occurred during a period of 14 days with local magnitudes between 1.4 and 2.4. We are not aware of similarly deep earthquakes in other regions of the EARS. A detailed study of these events can be found in Lindenfeld and Rümpker (2011).

Profile $C$ : This profile traverses the Rwenzoris in an area where the main block is connected with the northern ridge. Here we observe a strip of seismicity crossing the mountains in E-W direction (30-40 km on horizontal profile axis) with hypocentres between $10 \mathrm{~km}$ and $20 \mathrm{~km}$ depth. On the eastern side seismicity again extends from the surface down to $25 \mathrm{~km}$. Moho depths at NGIT and KASS are $25 \mathrm{~km}$ and $24 \mathrm{~km}$, respectively.

Profile D: This depth section starts beneath the central peaks of the Rwenzori block and crosses the Edward rift towards the eastern rift shoulder. Again, there is no seismic activity in the uppermost $10 \mathrm{~km}$ beneath the rift graben - similar as already observed beneath the Albert rift in profiles A-C. Moho depths close to the mountain (KILE, RUBO) are approximately $22 \mathrm{~km}$ which is about $5 \mathrm{~km}$ deeper than the maximum depth of seismicity in this area. Further to the east seismicity deepens systematically down to more than $25 \mathrm{~km}$. At the end of the profile, beneath the eastern rift shoulder the Moho discontinuity is located at $32 \mathrm{~km}$ depth (NYAN, RWEB).

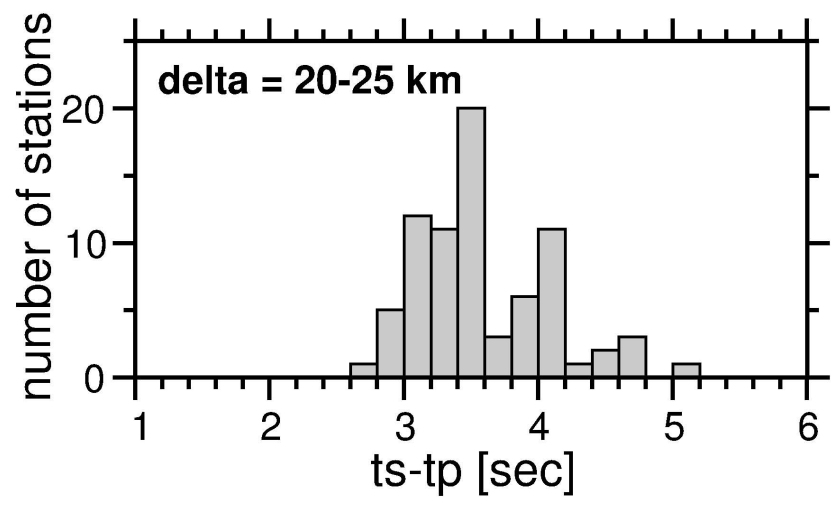

Fig. 10. Histogram of S-P travel-time differences observed at stations with epicentral distances between 20 and $25 \mathrm{~km}$. The hypocentres are located at the southern part of vertical section E1-E2 (Fig. 9). The bimodal distribution of $t_{S}-t_{P}$ confirms the observed seismic activity in 15 and $20-25 \mathrm{~km}$ depth, respectively.

Profile E: This profile runs east of the Rwenzoris, roughly in $\mathrm{N}-\mathrm{S}$ direction, parallel to the northward penetrating Edward rift. Again, there is no seismic activity within the uppermost $10 \mathrm{~km}$ beneath the rift valley. At its northern end (E2), where the profile leaves the tip of the rift, seismicity extends from the surface down to about $25 \mathrm{~km}$ depth. Further south the hypocentres concentrate at $15 \mathrm{~km}$ depth. Then the seismic activity splits up into two horizontal levels at $15 \mathrm{~km}$ and $25 \mathrm{~km}$ depth, respectively.

However, profile $\mathrm{E}$ is situated in the southern region with low station density and therefore the observed seismicity pattern may be an artefact due to the discontinuity of the velocity model at $15 \mathrm{~km}$ depth, as discussed in the introduction of Sect. 3.2. A histogram of travel-time differences between $\mathrm{S}$ - and P-waves is a simple means to verify the supposed bimodal depth distribution. For this purpose we selected a subset of events located at the southern part of profile E, were we observe a clear separation of seismic activity in $15 \mathrm{~km}$ and $20-25 \mathrm{~km}$ depth. Travel-time differences $\left(t_{S}-t_{P}\right)$ were calculated for epicentral distances between $20 \mathrm{~km}$ and $25 \mathrm{~km}$. The frequency distribution (Fig. 10) clearly indicates two maxima: a large one at $t_{S}-t_{P}=3.4 \mathrm{~s}$, corresponding to events in about $15 \mathrm{~km}$ depth and a smaller one at $t_{S}-t_{P}=4.0 \mathrm{~s}$, corresponding to the deeper events. A rough estimate for an epicentral distance of $23 \mathrm{~km}$ yields $t_{S}-t_{P}=3.4 \mathrm{~s}$ for a focal depth of $15 \mathrm{~km}$, and $t_{S}-t_{P}=4.0 \mathrm{~s}$ for focal depth of $23 \mathrm{~km}$, assuming $\mathrm{vp}=6.0 \mathrm{~km} \mathrm{~s}^{-1}$ and $\mathrm{vp} / \mathrm{vs}=1.74$. This estimate agrees well with the two peaks of the observed $t_{S}-t_{P}$ histogram and supports the thesis that seismic activity concentrates in two different depth levels in the southern part of profile E.

Furthermore, there is a remarkable coincidence between Moho depth and hypocentral depth extension, both increasing towards the south, although seismicity fades out and has a more diffusive character at the southern profile end. This 


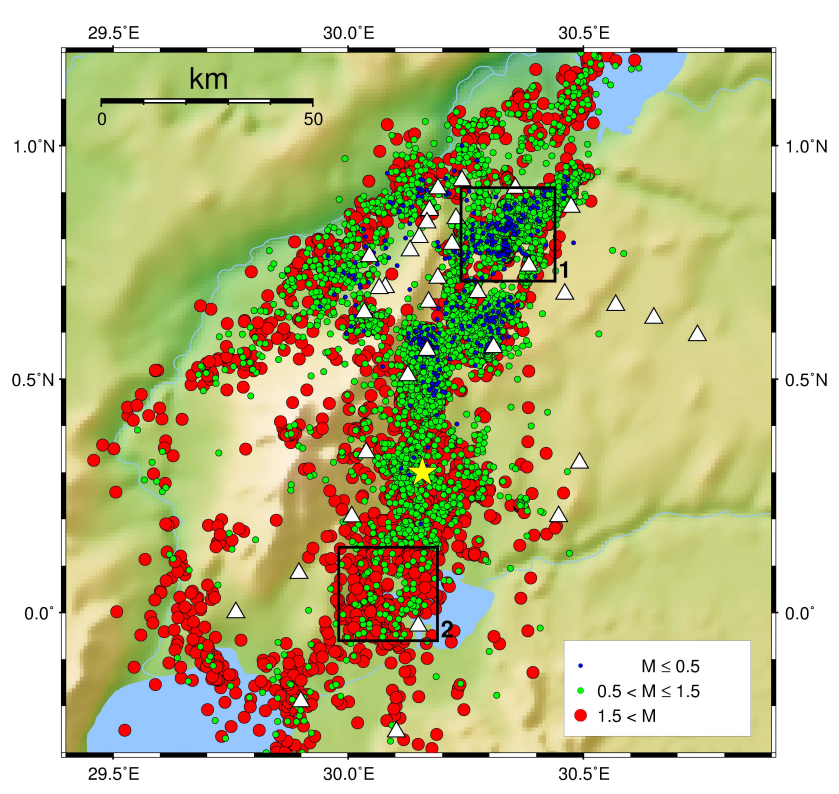

Fig. 11. Spatial distribution of the computed magnitudes. Coloured symbols represent different magnitude classes, see legend. White triangles indicate the station locations. Small events (green and blue symbols) could only be located in areas with high station density. This illustration is a clear indication that the apparent decrease of seismicity southwest of the Rwenzoris (cf. Fig. 2) is probably due to the lack of stations in this region. Two rectangles mark the areas where the magnitude-frequency relations presented in Fig. 12 were calculated. The yellow star marks the epicentre of the largest event that was recorded during the observation period (29 May 2006 $\left.15: 30, M_{L}=5.1\right)$.

is certainly due to the fact that we have to expect less location accuracy for events at the border of the station network. The seismicity seems to trace the upper and lower edge of a low velocity zone (LVZ) that was identified by receiver function inversion at station MWEY below $15 \mathrm{~km}$ depth and can be seen also beneath KASE and NYAN at similar depth but less pronounced (Wölbern et al., 2010). From modelling the authors derive a strong velocity decrease which is unlikely caused by compositional changes of the crustal rock (see S-velocity graph in Fig. 9). Wölbern et al. (2010) interpret this channel as a possible zone of partial melt within the crust related to local volcanic fields in the area. Reduced brittleness of the lower crust caused by increased temperature could explain the observed decrease of seismic activity between $15 \mathrm{~km}$ and $25 \mathrm{~km}$ depth in this area.

\subsection{Magnitude distribution}

Local magnitudes were calculated as specified in Sect. 2.2. The results for the complete data catalogue range from $M_{L}=$ -0.5 up to $M_{L}=5.1$ with a magnitude of completeness $M_{C}=1.3$ and a $b$-value of $\approx 1.1$, as derived from the cumulative magnitude-frequency distribution by a linear least squares fit. However, the map in Fig. 11 presents a highly het-

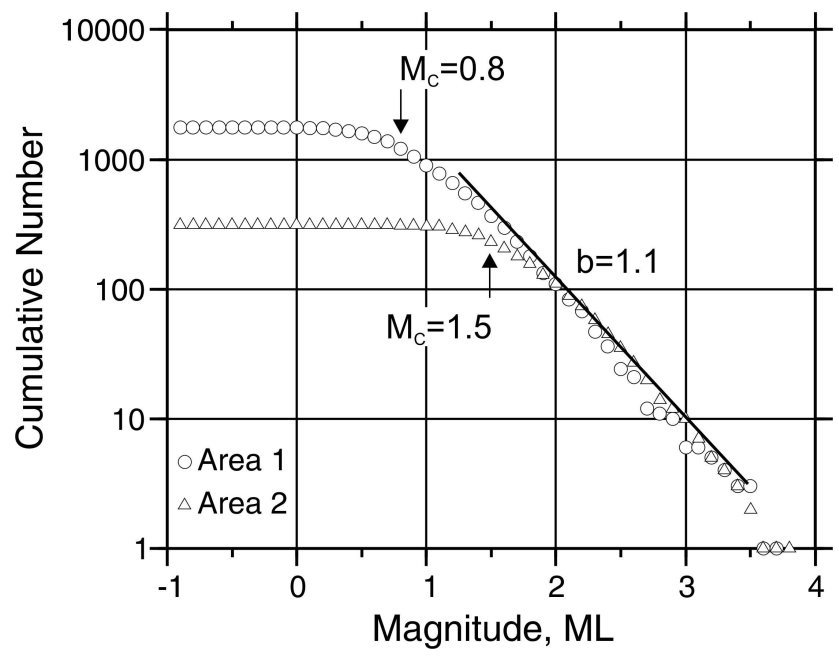

Fig. 12. Cumulative magnitude-frequency distribution for area 1 (circles) and area 2 (triangles), see Fig. 11. There is no significant difference between the slopes ( $b$-values) of the two distributions. Both areas exhibit a $b$-value slightly above 1 , but they show different magnitudes of completeness $\left(M_{C}\right)$.

erogeneous spatial distribution of the calculated magnitudes, which is obviously the result of the unevenly spaced station network. The smallest events with magnitudes $M_{L} \leq 1.5$ (green and blue symbols) could only be located in the northeastern area where the network has its highest density. In contrast, events with $M_{L}>1.5$ are located more evenly over the whole region. This implies that the apparently reduced seismic activity southwest of the Rwenzoris is probably due to the lack of stations in this area. The data of a recently deployed seismic network west of the mountains will prove if there is indeed similar high activity here as in the northeastern region. The largest event $\left(M_{L}=5.1\right)$ that was recorded during the observation period is marked in Fig. 11 with a yellow star.

The heterogeneous spacing of the station network implies also that the completeness of the recorded data set strongly depends on the respective region. Figure 11 presents the cumulative magnitude-frequency relations calculated for two different locations. Area 1 is situated in a region north of the Rwenzoris with high station density and the magnitudefrequency relation (circles) suggests a magnitude of completeness of $M_{C}=0.8$. The second area lies southeast of the mountains within the Edward rift. Here, the inter-station distances are relatively large and $M_{C}$ is approximately 1.5 (triangles). The $b$-value for both magnitude distributions is 1.1 which is slightly larger than the values published by Kebede and Kulhánek (1994) for the western branch of the East African Rift (0.9-1.0). According to Mogi (1967), $b$-values between 0.5 and 1.0 are indicative of tectonic processes in non-volcanic intraplate areas. Relatively large $b$-values (1.0$2.5)$ are usually observed in regions with active volcanism where seismicity is associated with eruptions and magma 
movements (e.g. Karpin and Thurber, 1987). However, the derived value of $b \approx 1.1$ is not significantly larger than the one for tectonic earthquakes. Hence, it does not allow to discriminate between magmatic and tectonic processes.

\subsection{Source mechanisms}

Fault plane solutions were derived from P-wave polarities and SV/P amplitude ratios. To achieve good data coverage we processed only events that were recorded by at least 12 stations. In total we analysed 304 events located in the Rwenzori area. $\mathrm{P}$ wave polarities were manually picked on the raw seismograms. Then we used a grid search algorithm to determine the orientation of the nodal planes (FOCMEC by Snoke et al., 1984). In general we were able to derive solutions without admitting $\mathrm{P}$ polarity errors. However, in many cases the nodal planes covered large angle ranges and it was impossible to derive a unique solution for the respective event. With P-polarities alone, we were able to determine reliable source mechanisms for only $40 \%$ of the selected earthquakes. To further constrain the nodal planes, we integrated also SV/P amplitude ratios into the grid search. In order to minimise the effects of different sensor bandwidths and local receiver conditions on the recorded amplitudes, we pre-processed the signals with a Butterworth band pass in the $0.1-5.0 \mathrm{~km}$ frequency range. Amplitudes were then picked on the vertical seismogram component. The combination of P-polarities with SV/P ratios enabled us to derive more reliable fault plane solutions than with P-polarities alone.

Figure 13 presents two applications of the procedure. In many cases it is not possible to derive unique solutions from $\mathrm{P}$-polarities alone. The results of the grid search are ambiguous (Fig. 13a). In this example the nodal planes are consistent with two different normal-faulting mechanisms of nearlyperpendicular strike directions, such that it is not possible to identify a single mechanism for this event. Performing a grid search with P-polarities together with SV/P amplitude-ratios restricts the possible source mechanism to normal faulting with NNE-SSW strike direction (Fig. 13b). The mechanism of the second event (Fig. 13c) is also not well constrained by P-polarities. The pattern of the nodal planes indicates normal faulting, and the red line represents an average orientation, however the variation is too large to specify reliable source parameters. The inclusion of amplitude ratios (Fig. 13d) yields the same fault-plane solution, but with improved significance. With this method we substantially increased the number of reliable solutions to almost $70 \%$ of the analysed events, compared to $40 \%$ using only P-polarities. Furthermore, in many cases we were able to improve the quality and significance of the P-polarity solutions.

A classification of the derived fault plane solutions on the basis of $\mathrm{P}$ - and T-axis plunge angles is presented in Fig. 14. Data points that are close to the three vertices of the graph represent pure normal faulting (red symbols), strike-slip (blue symbols), and reverse faulting (green symbols). Addi-
Table 2. Comparison of the derived source mechanisms: (A) from P-polarities alone, (B) combination of P-polarities and SV/P amplitude ratios.

\begin{tabular}{lcc}
\hline & A & B \\
\hline solutions in total & 197 & 304 \\
normal and normal with strike slip comp. & $79 \%$ & $72 \%$ \\
strike-slip & $3 \%$ & $8 \%$ \\
reverse and reverse with strike-slip comp. & $5 \%$ & $6 \%$ \\
odd & $14 \%$ & $14 \%$ \\
\hline
\end{tabular}

tionally, we classified normal faults with strike-slip component (magenta symbols), reverse faults with strike-slip component (cyan symbols), and odd mechanisms (grey symbols). As is expected for a rift structure with extensional stress regime, the majority of the derived source mechanisms represent pure normal faults or normal faults with strike slip component $(72 \%)$, whereas only $6 \%$ of all analysed events have pure reverse faults or reverse faults with strike-slip component; $8 \%$ of the events have pure strike-slip mechanisms.

The use of SV/P amplitude ratios to construct fault mechanisms bears several problems. Variable incidence angles influence the amplitude ratios at the free surface (Kisslinger et al., 1981) and local PS arrivals just before the S-wave affect the observed waveforms. For this reason we allow for a large tolerance of the amplitude ratio error which is defined as the deviation of the measured ratio from the theoretical one. This implies that the major constraints for an individual focal mechanism come from the P-polarities, whereas the amplitude ratios have a weaker influence. In no case did we derive fault-plane solutions from SV/P ratios alone. To estimate the reliability of the method we compared these results with the mechanisms obtained with P-polarities alone (Table 2). The percentage of the different mechanism types in relation to the total number of derived solutions is nearly the same for both methods. This indicates that the use of amplitude ratios does not cause a systematic bias on the results, but it enables us to derive more solutions than with P-polarities alone.

Figure 15 shows a map with all derived fault-plane solutions. The events are arranged into six groups in order to identify any systematic pattern. For each group the directions of the tension axes (T-axis trends) are plotted in a rosehistogram using sector widths of $15^{\circ}$. The results reveal a remarkable uniform picture for the orientation of the extensional stress field, particularly in groups 1,3 , and 4 which are located west and east of the Rwenzori Mountains. The average orientation of the T-axes in these groups is WNWESE - perpendicular to the rift axis - and in good agreement with kinematic rift models (Stamps et al., 2008, 2010). The two southernmost groups, 5 and 6 , show the same characteristic, but additionally there is a second prevailing T-axis orientation in WSW-ENE direction in both histograms. Group 2 is located northeast of the Rwenzori, immediate at the 


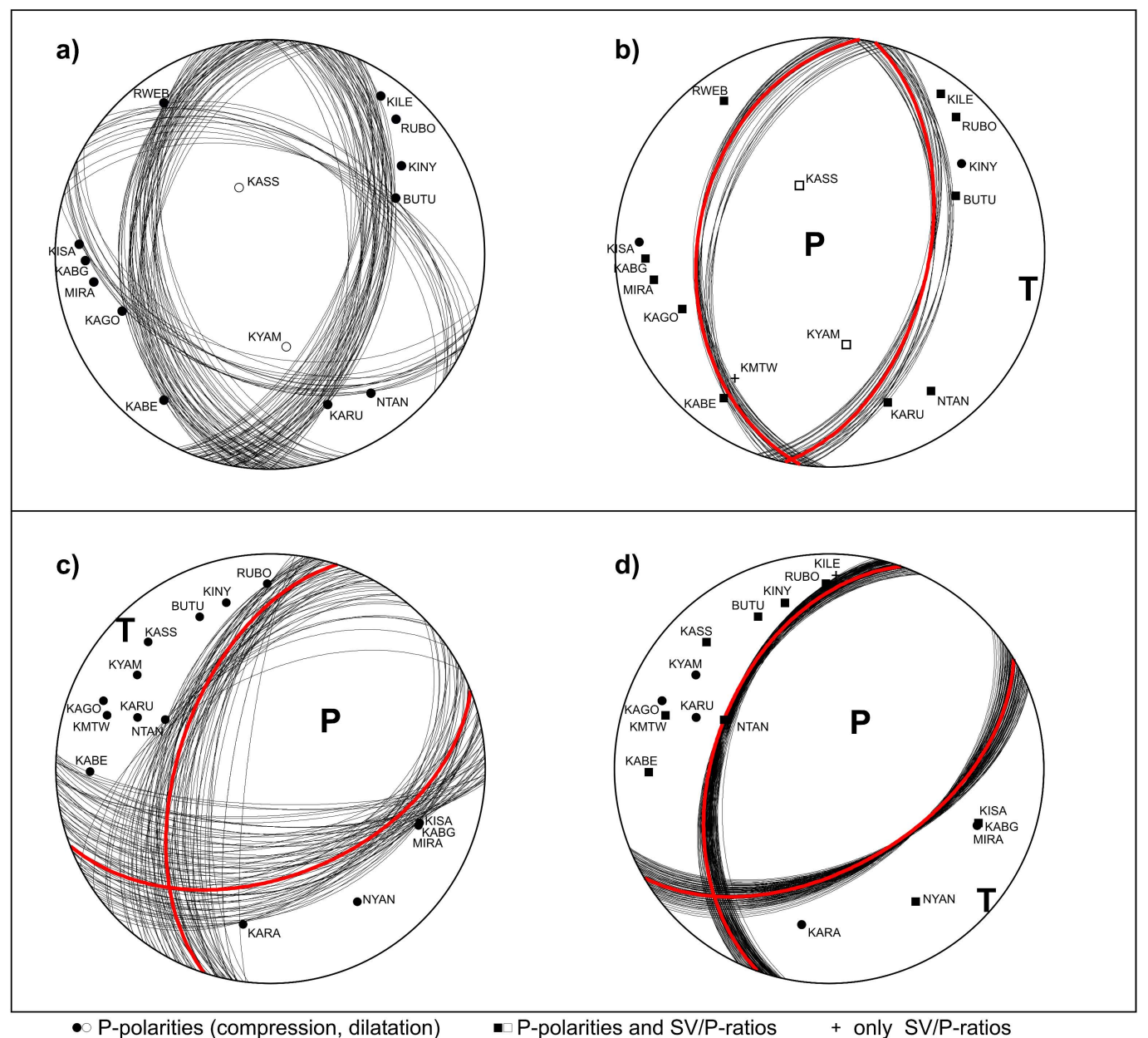

Fig. 13. Determination of fault plane solutions of two different events (upper and lower row). (a) Event I: Result of a grid search using only P-polarities. Open and closed symbols represent dilations and compressions, respectively. It is not possible to discern a unique source mechanism. (b) Event I: Grid search with the combination of P-polarities and SV/P ratios leads to a distinct solution. The red nodal line represents the mechanism that was finally assigned to this event. Pressure and Tension axis are marked with P and T respectively. (c) Event II: The result from P-polarities alone indicates normal faulting, however, the scatter of possible solutions is large. (d) Event II: Inclusion of amplitude ratios yields the same mechanism, but with improved significance.

eastern rift boundary fault, and reveals a completely different behaviour. T-axis trends are predominantly oriented NENSWS, which is more or less vertical to the T-axis orientation of all other groups. This might be an indication that the stress field in this area is controlled by local disturbances. Figure 15 presents also the CMT solution for the $M_{L}=5.1$ event from 29 May 2006. At that time only 7 stations of the network were running - not enough to calculate a stable fault plane solution from local recordings. The CMT was picked from the Global Centroid Moment Tensor database (www.globalcmt.org) and indicates normal faulting that fits well with the pattern of the locally analysed source mechanisms.

\section{Conclusions}

From February 2006 until September 2007 we have monitored the local seismicity in the Rwenzori Region with a network of 29 seismic stations. During this period a total of 13964 events were located with local magnitudes ranging from -0.5 up to 5.1. Magnitude-frequency relations show a $b$-value of 1.1 which is slightly above the values reported by other authors for the western rift. The magnitude of completeness, $M_{C}$, was derived for several subregions and exhibits a significant dependence on station density. $M_{C}=1.5$ in the southern parts of the area and $M_{C}=0.8$ in the northern parts where the average inter-station distance is considerably smaller. 


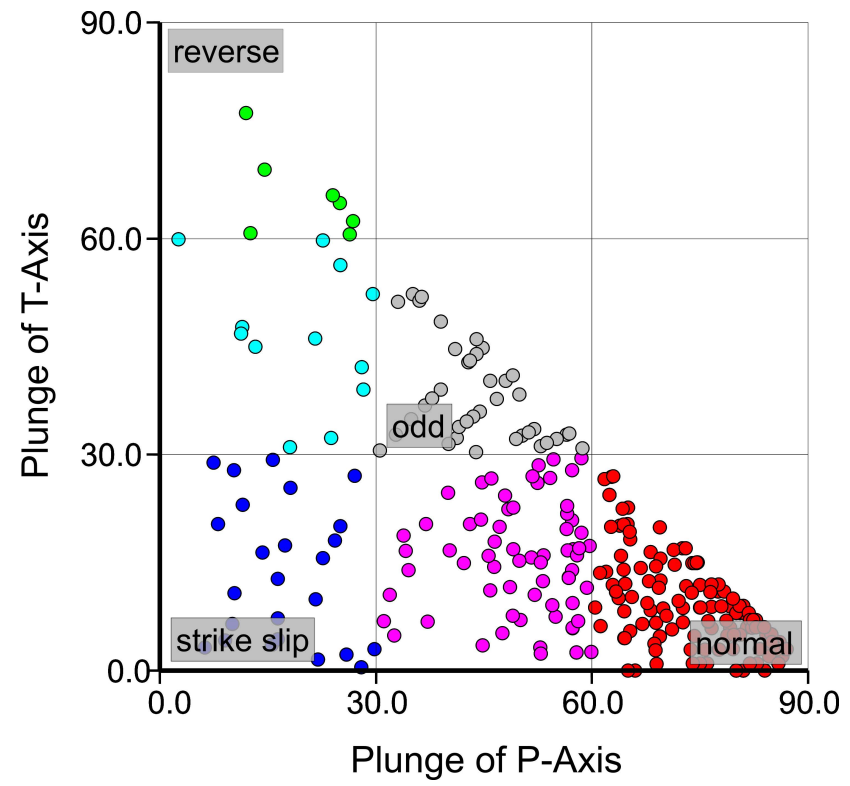

Fig. 14. Classification and frequency of all derived fault plane solutions (304 events) on the basis of $\mathrm{P}$ - and T-axis plunge angles. Red: pure normal faults (49\%). Magenta: normal faults with strike slip component $(23 \%)$. Blue: pure strike-slip mechanisms (8\%). Green: pure reverse faults (2\%). Cyan: reverse faults with strike-slip component $(4 \%)$. Grey: odd mechanisms (14\%).

The general focal-depth distribution shows that there is considerable seismic energy release down to $32 \mathrm{~km}$ depth with a pronounced peak of activity at $15 \mathrm{~km}$. Typically, there is no seismicity within the uppermost $10 \mathrm{~km}$ beneath the rift valley, whereas beneath the rift shoulders seismicity extends close to the surface. Vertical sections indicate that the maximum focal depths vary significantly within the Rwenzori area. However, they correlate fairly well with Moho depths that were derived by teleseismic receiver functions and range between $21 \mathrm{~km}$ and $34 \mathrm{~km}$. This confirms that the observed seismicity is restricted to the crustal part of the lithosphere, with the exception of seven events at a depth between 53 and $60 \mathrm{~km}$ as reported by Lindenfeld and Rümpker (2011). There is no indication for a crustal root beneath the Rwenzori Mountains, neither from receiver functions nor from focal depth distribution. This observation may be meaningful in view of the origin of the Rwenzoris. Usually, the buoyancy of thick crustal roots is thought to provide support for mountain topography. A missing root may be related to a relatively rapid uplift of the Rwenzoris.

Fault plane solutions were derived for 304 events using $\mathrm{P}$-polarities and SV/P-amplitude ratios. The majority of the source mechanisms are normal faults, only $2 \%$ of the analysed events are pure thrust faults. The T-axis trends give a uniform picture for the pattern of the extensional stress field. They are aligned in WNW-ESE direction, more or less vertical to the rift axis which is in good agreement with the expected rift process and also with kinematic rift models. Seis-

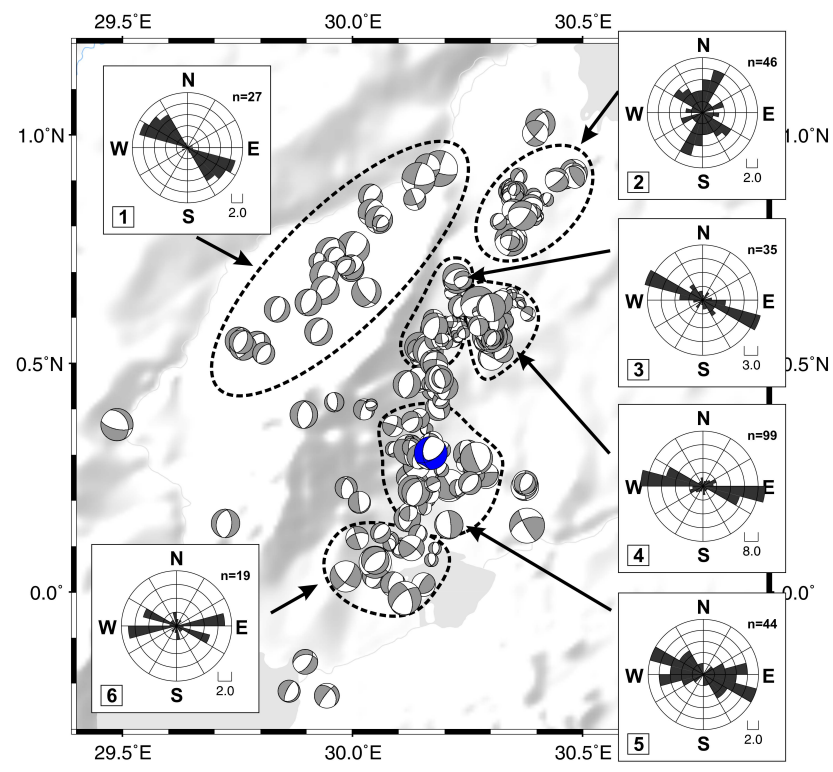

Fig. 15. Map of all fault-plane solutions. The events are arranged into six groups. The rose-histograms show the orientation of the Taxes in each group. The blue symbol represents the source mechanism of the $M_{L}=5.1$ event from 29 May 2006, as published by the Global Centroid Moment Tensor database (www.globalcmt.org), formerly the Harvard CMT catalogue (the symbol size of this event is not scaled by its magnitude).

micity southeast of the Rwenzoris is less resolved due to the inhomogeneous station distribution. Essential information on microseismic activity will be provided in the future by a recently deployed seismic network which covers also the area west and southwest of the Rwenzori Mountains.

Acknowledgements. Funding for this study was provided by the Deutsche Forschungsgemeinschaft (DFG) in the framework of the RiftLink research group (www.riftlink.org). We thank the Geophysical Instrumentation Pool Potsdam (GIPP) for providing the seismological equipment and GEOFON for archiving the data. The support of the Ugandan National Council for Science and Technology and of the Ugandan Wildlife Authority is greatly appreciated. Data processing and visualization was done with SEISAN and GMT software.

Edited by: T. Iwasaki 


\section{References}

Albaric, J., Déverchère, J., Petit, C., Perrot, J., and Le Gall, B.: Crustal rheology and depth distribution of earthquakes: Insights from the central and southern East African Rift System, Tectonophysics 468, 28-41, 2009.

Alsaker, A., Kvamme, L. B., Hansen, R. A., and Dahle, A.: The $M_{L}$ scale in Norway, Bull. Seismol. Soc. Am. 81, 379-398, 1991.

Bendick, R., McClusky, S., Bilham, R., Asfaw, L., and Klemperer, S.: Distributed Nubia-Somalia relative motion and dike intrusion in the main Ethiopian rift, Geophys. J. Int. 165, 303-310, 2006.

Brazier, R., Nyblade, A. A., and Florentin, J.: Focal mechanisms and the stress regime in NE and SW Tanzania, East Africa. Geophys, Res. Lett. 32, L14315, doi:10.1029/2005GL023156, 2005.

Bram, K.: Zum Aufbau der Kruste und des oberen Mantels im Bereich des westlichen Grabens des ostafrikanischen Grabensystems und im östlichen Zaire-Becken. Ergebnisse einer Untersuchung der Raumwellen von Nah-Erdbeben, Ph.D. thesis, Freie Universität Berlin, published by Dietrich Reimer Verlag Berlin, 1975.

Camelbeeck, T. and Iranga, M. D.: Deep crustal earthquakes and active faults along the Rukwa trough, eastern Africa, J. Geophys. Res. 124, 612-630, 1996.

Chen, W.-P. and Molnar, P.: Focal depths of intracontinental and intraplate earthquakes and their implications for the thermal and mechanical properties of the lithosphere, J. Geophys. Res. 88, 4183-4214, 1983.

Chorowicz, J.: The East African Rift System, J. Afr. Earth Sci. 43, 379-410, 2005.

Déverchère, J., Petit, C., Gileva, N., Radziminovitch, N., Melnikova, V., and San'kov, V.: Depth distribution of earthquakes in the Baikal rift system and its implications for the rheology of the lithosphere, Geophys. J. Int. 146, 714-730, 2001.

Ebinger, C. J.: Tectonic development and the western branch of the East African rift system, Geol. Soc. of Am. Bull. 101, 885-903, 1989.

Emmerson, B., Jackson, J., McKenzie, D., and Priestley, K.: Seismicity, structure and rheology of the lithosphere in the Lake Baikal region, Geophys. J. Int. 167, 1233-1272, 2006.

Foster, A. and Jackson, J. A.: Source parameters of large African earthquakes: implications for crustal rheology and regional kinematics, Geophys. J. Int. 134, 422-448, 1998.

Havskov, J. and Ottemöller, L.: Electronic Seismologist. SeisAn Earthquake Analysis Software, Seismol. Res. Lett. 70, 532-534, 1999.

Hutton, L. K. and Boore, D. M.: The $M_{L}$ scale in southern California, Bull. Seismol. Soc. Am. 77, 2074-2094, 1987.

Ibs-von Seht, M., Blumenstein, S., Wagner, R., Hollnack, D., and Wohlenberg, J.: Seismicity, seismotectonics and crustal structure of the southern Kenya Rift - new data from the Lake Magadi area, Geophys. J. Int. 146, 439-453, 2001.

Jackson, J., McKenzie, D., Priestley, K., and Emmerson, B.: New views on the structure and rheology of the lithosphere, J. Geol. Soc. 165, 453-465, 2008.

Jakovlev, A.: The crustal and upper mantle isotropic and anisotropic velocity structure beneath the Rwenzori Mountains from traveltime tomography, Ph.D. thesis, Goethe Universität Frankfurt am Main, 2010.

Jakovlev, A., Rümpker, G., Lindenfeld, M., Koulakov, I., Schumann, A., and Ochmann, N.: Crustal Seismic Velocities of the Rwenzori Region, East African Rift, from Local Travel-Time
Tomography: Evidence for Low-Velocity Anomalies beneath the Mountain Range, Bull. Seismol. Soc. Am. 101, 848-858, 2011.

Karpin, T. L. and Thurber, C. H.: The relationship between earthquake swarms and magma transport: Kilauea Volcano, Hawaii, Pure Appl. Geophys. 125, 971-991, 1987.

Kato, A., Kurashimo, E., Igarashi, T., Sakai, Sh., Iidaka, T., Shinohara, M., Kanazawa, T., Yamada, T., Hirata, N., and Iwasaki, T.: Reactivation of ancient rift systems triggers devastating intraplate earthquakes, Geophys. Res. Lett. 36, L05301, 1-5, doi:10.1029/2008GL036450, 2009.

Kebede, F. and Kulhánek, O.: Spatial and temporal variations of bvalues along the East African rift system and the southern Red Sea, Phys. Earth Planet. Inter. 83, 249-264, 1994.

Kisslinger, C., Bowman, J. R., and Koch, K.: Procedures for computing focal mechanisms from local (SV/P) ratios, Bull. Seismol. Soc. Am. 71, 1718-1729, 1981.

Koehn, D., Aanyu, K., Haines, S., and Sachau, T.: Rift nucleation, rift propagation and the creation of basement micro-plates within active rifts, Tectonophsics 458, 105-116, 2008.

Koehn, D., Lindenfeld, M., Rümpker, G., Aanyu, K., Haines, S., Passchier, C. W., and Sachau, T.: Active transsection faults in rift transfer zones: evidence for complex stress fields and implications for crustal fragmentation processes in the western branch of the East African Rift, Int. J. Earth Sci. (Geol Rundschau) 99, 1633-1642, 2010.

Langston, C. A., Brazier, R., Nyblade, A. A., and Owens, T. J.: Local Magnitude Scale and Seismicity Rate for Tanzania, East Africa, Bull. Seismol. Soc. Am. 88, 712-721, 1998.

Lienert, B. R. E. and Havskov, J.: A computer program for locating earthquakes both locally and globally, Seismol. Res. Lett. 66, 2636, 1995.

Lindenfeld, M. and Rümpker, G.: Detection of mantle earthquakes beneath the East African Rift, Geophys. J. Int. 186, 1-5, doi:10.1111/j.1365-246X.2011.05048.x, 2011.

Maasha, N.: The seismicity of the Rwenzori region in Uganda, J. Geophys. Res. 80, 1485-1496, 1975.

Maggi, A., Jackson, J. A., McKenzie, D., and Priestley, K.: Earthquake focal depths, effective elastic thickness, and the strength of the continental lithosphere, Geology 28, 495-498, 2000.

Midzi, V., Hlatywayo, D., Chapola, L. S., Kebede, F., Atakens, K., Lombe, D. K., Turyomugyendo, G., and Tugume, F. A.: Seismic harzard assessment in Eastern and Southern Africa, Ann. di Geofisica 42, 1067-1083, 1999.

Mogi, K.: Earthquakes and fractures, Tectonophysics 5, 35-55, 1967.

Nyblade, A. A. and Brazier, R. A.: Precambrian lithosphere controls on the development of the East African rift system, Geology 30, 755-758, 2002.

Nyblade, A. A. and Langston, C. A.: East African earthquakes below $20 \mathrm{~km}$ depth and their implications for crustal structure, Geophys. J. Int. 121, 49-62, 1995.

Ring, U.: Extreme uplift of the Rwenzori Mountains in the East African Rift, Uganda: Structural framework and possible role of glaciations, Tectonics, 27, TC4018, doi:10.1029/2007TC002176, 2008.

Shudofsky, G., Cloetingh, S., Stein, S., and Wortel, R.: Unusually deep earthquakes in East Africa: constraints on the thermomechanical structure of a continental rift system, Geophys. Res. Lett. 14, 741-744, 1987. 
Snoke, J. A., Munsey, J. W., Teague, A. C., and Bollinger, G. A.: A program for focal mechanism determination by combined use of polarity and SV-P amplitude ratio data, Earthquake Notes 55, 51, 1984.

Stamps, D. S., Calais, E., Saria, E., Hartnady, Ch., Nocquet, J. M., Ebinger, C. J., and Fernandes, R. M.: A kinematic model for the East African Rift, Geophys. Res. Lett. 35, L05304, doi:10.1029/2007GL032781, 2008.

Stamps, D. S., Flesch, L. M., and Calais, E.: Lithospheric buoyancy forces in Africa from a thin sheet approach, Int. J. Earth Sci. (Geol Rundschau) 99, 1525-1533, doi:10.1007/s00531-0100533-2, 2010.
Tugume, F. A. and Nyblade, A. A.: The depth distribution of seismicity at the northern end of the Rwenzori mountains: implications for heat flow in the western branch of the East African Rift System in Uganda, South Afr. J. Geol. 112, 261-271, 2009.

Twesigomwe, E. M.: Seismic hazards in Uganda, J. Afr. Earth Sci. 24, 183-195, 1997.

Wölbern, I., Rümpker, G., Schumann, A., and Muwanga, A.: Crustal thinning beneath the Rwenzori region, Albertine rift, Uganda, from receiver-function analysis, Int. J. Earth Sci. (Geol Rundschau) 99, 1545-1557, 2010.

Young, P. A. V., Maguire, P. K. H., d'A. Laffoley, N., and Evans, J. R.: Implications of the distmribution of seismicity near Lake Bogoria in the Kenya Rift, Geophys. J. Int. 105, 665-674, 1991. 